\title{
Polling in a proportional representation system
}

\author{
Christos Mavridis $^{1}{ }_{(D)}$ Ignacio Ortuño-Ortín ${ }^{2}$
}

Received: 8 May 2017 / Accepted: 4 February 2018 / Published online: 14 February 2018

C The Author(s) 2018. This article is an open access publication

\begin{abstract}
We study the effects of opinion polls on election results in proportional representation systems. Moderate voters have preferences over the vote shares received by the parties so that an agent's optimal voting decision might depend on the other agents' behavior. A voter's information about other voters' behavior can be improved through a series of opinion polls. We show that the mass of undecided voters decreases monotonically with the number of polls, but may not necessarily disappear. Voters who remain undecided have centrist ideologies. On average a series of polls brings the society closer to complete information even though specific polls may push the election result away from the complete information case.
\end{abstract}

\section{Introduction}

The effects that opinion polls have on the electorate have been studied extensively. The conclusion of the literature is that the publication of polls influences how the electorate votes (Myerson and Weber 1993; Morton et al. 2015). This influence is the reason why many countries have restrictions on how, when and if a poll should be published. Chung (2012) provides information about poll restrictions in 83 countries and finds existence of a blackout period for pre-election opinion polls in 38 of them. The restrictions can range from a ban on publishing polls for a specific time before

Christos Mavridis

c.mavridis@lancaster.ac.uk

Ignacio Ortuño-Ortín

iortuno@eco.uc3m.es

1 Department of Economics, Lancaster University, Bailrigg, Lancaster LA1 4YX, UK

2 Department of Economics, Universidad Carlos III de Madrid, Calle Madrid 126, 28903 Getafe, Madrid, Spain 
the election, like in Italy (15 days) or in Greece (15 days until 2014, 1 day since), to an outright ban during the entire campaign period like in Singapore. In the last decade in many countries there have been public discussions on whether these types of restrictions should be posed or lifted. In 2012 India's Chief Election Commissioner stated that opinion polls and exit polls should both be banned. ${ }^{1}$ A 2013 survey in the United Kingdom, where there is not a ban on publishing pre-election opinion polls, showed that three out of ten MPs supported the idea of such a ban. ${ }^{2}$

These restrictions and discussions show that the issue of the interaction between opinion polls and elections is important both from a theoretical and from a practical point of view. The motive behind such bans is usually to let the electorate vote "trully" without the influence of the results of opinion polls, an influence which is perceived as bad. The fear that polls may be biased, in which case the electorate might base its decision on false information, is often used to argue in favor of restrictions. Another argument is that basing the decision itself on the information generated by opinion polls might distort the election results away from the "true" preferences of the electorate. ${ }^{3}$ On the other hand, opinion polls are useful inasmuch as they clear some uncertainty in the political environment leading to more efficient decision making by political actors. Examples of uncertainty include uncertainty about valence of the candidates as e.g. in Kendall et al. (2015) or on the actual policy-ideology of candidates as in Baron (1994).

In democracies with proportional representation system where parties compete for parliament seats, these seats can be seen as a measure of political power; a ruling party that controls enough seats to just secure a majority might be more moderate in its policies than a party that controls a larger fraction of the parliament. For this reason a moderate voter may choose not to vote for her favorite party if she feels that it may be too strong. Therefore a moderate voter who is happier with a more equal (or a particular) split of parliamentary seats would like to know how the rest of the voters will vote before she decides her own vote, implying that she would need to have some information about the distribution of the rest of the voters. This idea can be seen, for example, in McMurray (2017) or in Morton et al. (2015). In an experimental study Ceci and Kain (1982) show that moderate voters, when instructed that the latest poll showed that a candidate " commanded a substantial lead over the other", tend to report that they would vote for the trailing one.

The goal of this paper is to examine the effects that opinion polls might have in the behavior of voters in proportional representation systems. In particular, we analyze under what conditions the publication of opinion polls during the electoral campaign leads to complete information. To do so, we construct a simple two-party proportional representation system with a continuum of voters and fixed policy proposals. It is

\footnotetext{
1 Opinion, exit polls have no scientific basis: CEC (April 28, 2012). IBNLive. Retrieved from: http:// ibnlive.in.com/news/opinion-exit-polls-have-no-scientific-basis-cec/252787-3.html.

2 Eaton, David. Should pre-election opinion polls be banned? A third of MPs think so (November 13, 2013). NewStatesman. Retrieved from: http://www.newstatesman.com/politics/2013/11/should-preelection-opinion-polls-be-banned-third-mps-think-so.

3 Morton et al. (2015) identification strategy exploits a 2005 French voting reform that came into place precisely to a avoid the situations where exit polls were public before some voters went to vote.
} 
assumed that the implemented policy is a combination of the parties' proposals with weights given by their vote shares. Voters care about the implemented policy, which implies that they have preferences over the vote shares received by the parties. Even though there is a continuum of voters we will assume that they behave as if they could have some (small) impact on the electoral outcome. In this case, an agent's optimal voting decision might depend on the other agents behavior. Voters have incomplete information about each other's preferences and therefore about their voting behavior. A voter's information about other voters' preferences can be improved through a series of polls. Polls provide information on the percentage of people who declare that they will vote for each party as well as the percentage of undecided people. It is assumed that agents always respond honestly to the questions in the opinion polls. It turns out that the agents most likely to report that they do not know what they will vote yet are the more moderate ones.

The paper first shows under which conditions on the distribution of citizens' preferences a sequence of polls will be able to reveal the complete information case. With every poll the undecided mass of agents decreases, as more citizens are sure of what to vote. After enough polls agents have (almost) complete information. However, for other distributions of voters' preferences, after a number of polls the undecided mass of agents stops decreasing and additional polls cannot provide any further information. The paper also shows that the implemented policy is not monotonic in the number of polls: the publication of one last additional poll before the election may result in an implemented policy that is further away from the policy that would result under complete information.

To the best of our knowledge this is the only paper that examines polls and proportional representation together in a dynamic setting. It is also important to mention that this model provides three predictions: (1) the positive correlation between undecidedness and centrist ideologies, (2) the non-monotonicity of vote shares with respect to the number of opinion polls and (3) the decrease of the mass of undecided voters when more polls are published. As explained below, each of these three predictions can be also generated by other models but we do not know of any model that predicts the three of them at the same time.

\subsection{Related literature}

Many papers have examined how opinion polls affect voters and parties through the information they reveal. Denter and Sisak (2015) show that poll results affect campaigning spending which in turn affect how voters vote. Bernhardt et al. (2009), Morgan and Stocken (2008) and Meirowitz (2005) show that polls are used to clear uncertainty over voters preferences, but at the same time this can give rise to strategic poll answering on behalf of the voters. McKelvey and Ordeshook (1985) show that polls create a "bandwagon" effect in favor of the leading party, while Goeree and Großer (2006) and Taylor and Yildirim (2010) show that the opposite "underdog" effect can appear through the mobilization of the voters of the trailing party. In both of these papers it is argued that through polls it is possible that the "wrong" side may win. Klor and Winter (2006) show in an experiment that in both close and lopsided elections polls 
have a bandwagon effect, and in a later paper (Klor and Winter 2014) they use US Gubernatorial elections data to show that the increase in participation in elections is greater for the supporters of the leading candidate. Großer and Schram (2010) find similar results. Herrmann (2014) examines polls under proportional representation and shows that voters act strategically, trying to anticipate the future coalitions after the election takes place. In his model there are three types of voters using the results of polls to vote strategically in order to influence the future coalitions, while in our model there is a continuum of voters whose voting intentions have a dynamic relationship with poll results.

The implemented policy seen as a compromise among different ideological sides, or power sharing, is not a new idea (Alesina and Rosenthal 1996; Grossman and Helpman 1996; Llavador 2006; Sinopoli and Iannantuoni 2007; Saporiti 2014; Matakos et al. 2015, 2016; Herrera et al. 2015) . Ortuño-Ortín (1997) discusses a two-party setting where implemented policy is a convex combination of the two parties' platforms generated using a continuous function of the parties' shares in the election. Sahuguet and Persico (2006) point out that in a proportional system parties need to maximize their share (rather the probability of getting at least $50 \%$ of the vote) and that the implemented policy is at least partly influenced by the minority party.

Herrera et al. (2015), in a proportional representation setting similar to the one of this paper, show that the "marginal voter's curse" has the effect that voters with low quality information abstain and do not vote for fear of casting a vote for the wrong side. Finally, voters may choose to support the party to which they feel least ideologically close, an idea which is shared by the concept of the "protest vote" by which voters may want to punish, or control the power of their favorite party (see eg. Myatt 2017).

The rest of the paper is organized as follows. Section 2 develops the model and provides the main results about the possible convergence to the full information case. Section 3 concludes.

\section{Model description}

We assume a uni-dimensional policy space $D \subset \Re$. The voters have single-peaked preferences over this policy space and their optimal policies are distributed over $D$ according to a distribution function $F(\cdot)$ which is assumed to be continuous, strictly increasing and differentiable with a corresponding density function $f(\cdot)$. We identify a voter's type with her ideal policy. The utility of a voter of type $x \in D$ from the implemented policy $\widehat{x}$ is given by the function $v(|\widehat{x}-x|)$, i.e. it is a function of the absolute distance between $x$ and the implemented policy $\widehat{x}$. Function $v(|\widehat{x}-x|)$ is decreasing and concave in $|\widehat{x}-x|$ and it has a unique maximum at $\widehat{x}=x$ such that $v(0)=0$. These mean that the utility function of a voter is symmetric around her optimal policy point where the utility is maximum and normalized to zero. There are two parties running in the election, $L$ and $R$, each having a fixed policy position at 0 and 1 respectively. The actual implemented policy, $x(p)$, will be a compromise between those two policy positions, namely:

$$
x(p)=(1-p) \times 0+p \times 1=p,
$$


Table 1 Decision of a voter at 0.4

\begin{tabular}{lll}
\hline$L$ share & Implemented policy & Decision \\
\hline 0.8 & 0.2 & $R$ \\
0.3 & 0.7 & $L$ \\
\hline
\end{tabular}

where $p$ is the share of votes party $R$ gets. This share is defined as $p=\frac{m_{R}}{m_{L}+m_{R}}$, with $m_{L}$ and $m_{R}$ being the voter masses that voted for $L$ and $R$ respectively, meaning that the parties' shares are calculated over the mass of voters that actually voted. If $u$ is the mass of the citizens that decide not to vote then $m_{L}+m_{R}+u=1$. The setting is similar to Ortuño-Ortín (1999). Since $x(p)=p$ we use $p$ to describe the vote share received by $R$ as well as the implemented policy.

Notice that $p=\frac{m_{R}}{m_{L}+m_{R}}$ implies that the parties' shares of influence in the implemented policy are equal to their vote shares. ${ }^{4}$ Even though this assumption is made for simplicity and clarity, all the results follow if we instead assume the more flexible weight function

$$
\hat{p}=\frac{\left(\frac{m_{R}}{m_{L}+m_{R}}\right)^{\gamma}}{\left(\frac{m_{R}}{m_{L}+m_{R}}\right)^{\gamma}+\left(\frac{m_{L}}{m_{L}+m_{R}}\right)^{\gamma}}
$$

with $\gamma \geq 1$ and finite as in, for example, Saporiti (2014) and Matakos et al. (2015, 2016). Obviously, for $\gamma=1, p=\hat{p}$. As $\gamma$ increases then the share of the bigger party increases, and that of the smaller party decreases. This captures the fact that some parliamentary systems, while mostly proportional, give some bonus seats to the biggest party or demand a certain percentage threshold to be passed before they assign seats to smaller parties.

Given that there is a continuum of agents, no single agent can affect the implemented policy. We assume, however, that agents want to behave as if anybody could move the implemented policy in certain direction. Thus, if an agent $x>p$ voted for $L$, after the outcome is revealed, she will regret the way she voted. Even though her vote could not change anything she voted in the "wrong direction." For this reason, each voter would like to know how the other voters are behaving before she chooses which party to vote for. Consider Table 1 where we analyze the decision of a voter located at 0.4. This voter is closer to 0 than to 1 , but if she expects that too many voters will vote for the left party (first row) the implemented policy will be on her left and therefore she would like to vote for party $R$.

\subsection{Complete information equilibrium}

If the distribution function $F(\cdot)$ is common knowledge we can easily describe the behavior of voters. Let $\sigma_{x}$ denote the vote strategy chosen by agent $x$. We assume that $\sigma_{x} \in\left\{\sigma_{x}^{L}, \sigma_{x}^{R}, \sigma_{x}^{1 / 2}\right\}$. The interpretation is that $\sigma_{x}^{L}\left(\sigma_{x}^{R}\right)$ means a vote for $L(R)$ and

\footnotetext{
4 Under this formulation an alternative interpretation of the voters' utility is that they have direct preferences over the parties' shares themselves.
} 
$\sigma_{x}^{1 / 2}$ means that with probability $1 / 2$ the agent votes for $L$. Let $\sigma=\left(\sigma_{x}\right)_{x \in \Re}$ be a list of strategies one for each type of agent and let $p(\sigma)$ be the associated percentage of votes obtained by party $R$.

Definition 1 A list of strategies $\sigma=\left(\sigma_{x}\right)_{x \in \mathfrak{R}}$ constitutes a complete information voting equilibrium (CIVE) if $\forall x \in D$ :

$$
\begin{aligned}
& \sigma_{x}=\sigma_{x}^{L} \text { implies } p(\sigma)>x, \\
& \sigma_{x}=\sigma_{x}^{R} \text { implies } p(\sigma)<x, \\
& \sigma_{x}=\sigma_{x}^{1 / 2} \text { implies } p(\sigma)=x .
\end{aligned}
$$

The equilibrium concept is similar to the one in Gerber and Ortuño-Ortín (1998). It is not difficult to see that our CIVE is a standard strong Nash equilibrium. An agent votes to move the implemented policy toward her ideal policy. Even though she cannot do it on her own, she might believe that people with types close to hers will behave in the same way. In equilibrium there is no set of agents (with positive measure) that can deviate from their strategies and change the outcome in a beneficial way for all of them.

Notice that the equilibrium defines a cut-off point $x^{*}=p(\sigma)$ that divides the electorate in two parts: all agents to the left (right) of the implemented policy vote for $L(R)$.

Theorem 1 There always exists a unique complete information voting equilibrium $\sigma^{*}$ characterized by the cut-off point $x^{*}=1-F\left(x^{*}\right)$.

Proof By continuity of $F(\cdot)$ the point $x^{*}$ exists, and by strict monotonicity this point is unique. Now, let $x^{*}$ be the implemented policy. Then strategy profile $\sigma^{*}$ implies that the voters to the left of $x^{*}$ vote for $L$ and the ones to the right of $x^{*}$ vote for $R$. Notice that the mass of voters of type $x^{*}$ is zero, so that the mass of voters of $L$ is $F\left(x^{*}\right)$ and the mass of voters of $R$ is $1-F\left(x^{*}\right)$. In turn, these masses give rise to the implemented policy $x^{*}=0 \times F\left(x^{*}\right)+1 \times\left(1-F\left(x^{*}\right)\right)=1-F\left(x^{*}\right)$, which proves that an equilibrium always exists, and since $x^{*}$ is unique there is only one equilibrium defined by $x^{*}=1-F\left(x^{*}\right)$.

The last step is to show that there is no other equilibrium. Suppose that there is an equilibrium implemented policy $x^{\prime *} \neq x^{*}$. The equilibrium strategy implies that everybody to the left (right) of $x^{\prime}$ vote for $L(R)$, giving rise to the implemented policy $x^{\prime \prime}=1-F\left(x^{\prime}\right)$, but we have that $x^{\prime \prime} \neq x^{\prime}$, which leads to a contradiction.

Notice that $x^{*}=1-F\left(x^{*}\right)$ does not necessarily correspond to the median policy $x^{M}, F\left(x^{M}\right)=1 / 2$. The only case in which we obtain a "median voter outcome" is when $x^{M}=1 / 2.5$

\subsection{Polls}

When the distribution of voters is common knowledge, voters can calculate $x^{*}=1-F\left(x^{*}\right)$ and infer what they should vote. However, when the distribution

5 Since in this case we would have $\frac{1}{2}=1-F\left(\frac{1}{2}\right)$, so $F\left(\frac{1}{2}\right)=\frac{1}{2}$. 
is no longer known to the voters, we have incomplete information, and some voters do not have enough information to be certain which party they should vote for. For some other agents this will not be a problem. For example, any agent of type $x<0$ will always vote for $L$ regardless what other agents do. Thus, it is clear that all agents with type outside the interval $[0,1]$ have a dominant strategy. We will call agents with $x<0$ as left partisans and agents $x>1$ as right partisans. It will be useful to denote by $\rho_{L}$ the mass of left partisans, and by $\rho_{R}$ the mass of right partisans, i.e. $\rho_{L}=F(0)$ and $\rho_{R}=1-F(1)$. We denote the agents in $[0,1]$ as moderate. These agents have no dominant strategies, but the only relevant information they need to calculate their optimal strategy is the share of votes that each party will get. It can be argued, then, that polls can provide this information. The problem is, however, that "Voting intentions may change from day to day as the voters' perceptions evolve during a campaign, so that a poll, when published, may invalidate itself." (Myerson and Weber 1993, page 102). The question then is to find under which circumstances the election under incomplete information and polls leads to the same outcome as when the distribution of agents' types is common knowledge. The answer to this question depends very much on the assumptions on voters' beliefs and the way they use the information provided by the polls. Here we will adopt a very simple model to deal with those issues that will yield clear results. We believe, however, that the basic results are robust to more general specifications as we discuss below.

We suppose that there is a sequence of polls at periods $t=0,1,2, \ldots, T-1$. The election takes place at period $T$. The question asked is: "what are you going to vote on the day of the election?" For $t<T$ we write $v_{x, t}^{i}, i \in\{0,1, \emptyset\}$ to denote the voting intention that agent $x$ (if asked) declares in period $t$. Thus, $v_{x, t}^{0}\left(v_{x, t}^{1}\right)$ denotes that $x$ will vote for $L(R)$ and $v_{x, t}^{\emptyset}$ denotes that $x$ does not know yet. This possibility of "indecision" is essential in our model. This is also a very common feature in many real elections.

A poll at the end of period $t$ is a vector $P_{t}=\left(\varepsilon_{t}, u_{t}\right)$ such that $\varepsilon_{t}$ is the percentage of people that, during period $t$, announced the intention to vote for $L$ and $u_{t}$ the percentage of people who announced not to know yet which party they will vote for. Thus we see a poll as providing information on current intentions (in this sense a poll is not a prediction of the election outcome). We assume that $P_{t}$ is a statistically perfect poll and appropriately samples and measures voting intentions at that period. We may write the outcome of the election as $\varepsilon_{T} \equiv\{$ percentage of voters who vote for $L$ \}.

At each period $t=0,1, \ldots, T-1$ agent $x$ has subjective beliefs on the outcome $\varepsilon_{T}$ given by $\beta_{x, t}$. These beliefs are characterized by a CDF on $[0,1]$, i.e. $\beta_{x, t}(y)=$ Probability $\left\{\varepsilon_{T} \leq y\right\}$. In general $\beta_{x, t}$ will depend on the original beliefs $\beta_{x, 0}$ and the information provided by the polls $P_{t^{\prime}}, t^{\prime}<t$. Define

$$
\begin{aligned}
& m_{x, t}=\sup \left\{y: \beta_{x, t}(y)=0\right\} \\
& M_{x, t}=\inf \left\{y: \beta_{x, t}(y)=1\right\} .
\end{aligned}
$$

We suppose that at period $t=0,1, \ldots, T-1$, agent $x$ responds to a poll in the following way: 


$$
v_{x, t}= \begin{cases}v_{x, t}^{1} & \text { if } m_{x, t} 0+\left(1-m_{x, t}\right) 1<x \\ v_{x, t}^{0} & \text { if } M_{x, t} 0+\left(1-M_{x, t}\right) 1 \geq x \\ v_{x, t}^{\emptyset} & \text { otherwise }\end{cases}
$$

Expression (1) just says that an agent answers that her vote will be for, say, $R$ if the implemented policy can never be, according to her beliefs, to the right of her ideal policy. This is equivalent to saying that agents want to rule out the possibility of regret, i.e., the possibility that later on they do something different from what they had stated. Thus, agents only announce their vote intention when they are quite sure about it.

This may be seen as a very ad hoc feature of our model. We believe, however, that there is some intuitive justification for it. Moreover, the results in this paper are robust to changes that allow for more "flexible" rules. Thus, suppose that agents announce their vote intentions even though they are not completely sure about their final vote. The results would be similar to the ones provided here as long as agents believe that with a high enough probability they will vote for the same party they said they were going to vote. ${ }^{6}$

Now we have to describe the way people vote at period $T$. There are several ways to model this decision problem. Here we will assume that voters follow the rule in (1) ${ }^{7}$

A type $x$ agent will vote for $L(R)$ only if the expected implemented policyaccording to her subjective beliefs-is to the right (left) of $x$. In the case the expected implemented policy coincides with the ideal policy an agent will vote with probability 0.5 for $L$ (this is not essential and we could, alternatively, assume that she does not vote). Notice that the rule in (1) implies that agents who are undecided at period T do not vote.

One might object against this type of behavior because it does not depend on the utility function. It turns out that this is not a problem in our model. Agents who were not undecided at period $T-1$ will not be undecided at period $T$ either, so their behavior would not change if we introduce the expected utility in (1). The problem arises with people who at period $T$ - the election day-do not know yet if the outcome will be to the right or the left of their ideal policies. In principle, it seems more reasonable to assume that they consider the expected utility rather than the expected outcome. This alternative, however, would not change the type of qualitative results provided in this paper and so we stick to (1) for simplicity. Our results are also robust to other decision criteria for the undecided agents on the day of the election.

\footnotetext{
6 An alternative approach would assume that an agent announces her vote for the party that, for example, in expected terms is more likely to be the one she finally votes for. This, however, would rule out the possibility of undecided agents. Moreover, this approach requires more information than the one we assume here about the way agents change their beliefs $\beta_{x, t}$.

7 Another possible rule is to assume that the relevant variable is the expected value of the implemented policy. Thus, at period $T$ agent $x$ votes in the following way:
}

$$
\sigma_{x}= \begin{cases}\sigma_{x}^{0} & \text { if } \int_{0}^{1}(x-\varepsilon) d \beta_{x, t}(\varepsilon)<0 \\ \sigma_{x}^{1} & \text { if } \int_{0}^{1}(x-\varepsilon) d \beta_{x, t}(\varepsilon)>0 \\ \sigma_{x}^{1 / 2} & \text { otherwise. }\end{cases}
$$


Now we must specify the way beliefs may change through time. Let $P_{t-1}=\left(\varepsilon_{t-1}, u_{t-1}\right)$ be the information provided by the poll at the end of period $t-1$. Then the beliefs at period $t$ are such that for all $x$

$$
\begin{aligned}
& M_{x, t}=\varepsilon_{t-1}+u_{t-1} \\
& m_{x, t}=\varepsilon_{t-1} .
\end{aligned}
$$

Here we are saying that agents believe that the number of votes that $L(R)$ will get cannot be less than $\varepsilon_{t-1}$ (more than $\varepsilon_{t-1}+u_{t-1}$ ). Notice that this restriction is compatible with the possibility that the ratio of votes in favor of $L$ over votes in favor of $R$ changes over time. The equalities in (2) also imply that, at period $t$, agents believe that with some positive probability (almost) all undecided agents will vote $L$ and with some positive probability (almost) all undecided agents will vote $R$. In other words, this assumption captures the idea of a very imperfect information on the distribution of types. Since the expressions in (2) are the same for all agents we can drop the subscript and write $M_{t}$ and $m_{t}$.

We must now specify the beliefs agents have at period $t=0$, when no poll has been conducted yet. We will assume - consistent with the idea that agents have a very imperfect information on $F$-that first period beliefs, $\varepsilon_{x, 0}$, are such that only agents outside the interval $(0,1)$ will be sure about the party they will vote for. Therefore, we have that $P_{0}=\left(\varepsilon_{0}, u_{0}\right)$, where $\varepsilon_{0}=F(0)$ and $u_{0}=F(1)-F(0)$. Recall that we denote by $\rho_{L}$ the mass of left partisans, and by $\rho_{R}$ the mass of right partisans, i.e. $\rho_{L}=F(0)$ and $\rho_{R}=1-F(1)$, so that we can also write the initial beliefs as $P_{0}=\left(\rho_{L}, 1-\rho_{R}-\rho_{L}\right)$.

We know that after publishing poll $P_{t}=\left(\varepsilon_{t}, u_{t}\right)$ all agents know that the final implemented policy will lie in the interval $\left[l_{t}, r_{t}\right] \subseteq[0,1]$ where

$$
\begin{aligned}
l_{t} & =1-M_{t} \\
r_{t} & =1-m_{t} .
\end{aligned}
$$

Indeed, if all the undecided agents at period $t$ finally vote for party $L$ the implemented policy would be $l_{t}=0 \times M_{t}+1 \times\left(1-M_{t}\right)=1-\varepsilon_{t-1}-u_{t-1}$, and if all of them vote for party $R$ the implemented policy would be $r_{t}=0 \times m_{t}+1 \times\left(1-m_{t}\right)=1-\varepsilon_{t-1}$. Thus, after poll $t$ is published the set of still undecided agents coincides with the interval $\left[l_{t}, r_{t}\right]$ and, given all our above assumptions, when poll $t+1$ is conducted agents with $x<l_{t}\left(x>r_{t}\right)$ will respond that they will vote for $L(R)$, and agents $x \in\left[l_{t}, r_{t}\right]$ will declare to be undecided.

We are interested in the sequence of polls and elections outcomes

$$
P_{0}=\left(\varepsilon_{0}, u_{0}\right), P_{1}=\left(\varepsilon_{1}, u_{1}\right), \ldots, P_{T-1}=\left(\varepsilon_{T-1}, u_{T-1}\right), \varepsilon_{T} .
$$

Let $\varepsilon^{*}$ denote the vote share obtained by $L$ in the complete information case. If polls are good aggregators of information we should observe $\varepsilon_{T}=\varepsilon^{*}$, or at least $\lim _{T \rightarrow \infty} \varepsilon_{T}=\varepsilon^{*}$. (By $T \rightarrow \infty$ we mean that the number of polls, before the election day, goes to infinity). A sufficient condition for this to happen is that 


$$
\lim _{T \rightarrow \infty}\left(\varepsilon_{T-1}, u_{T-1}\right)=\left(\varepsilon^{*}, 0\right)
$$

At period $t=0$ we have $P_{0}=\left(\varepsilon_{0}, u_{0}\right)$. Now it is quite straightforward to calculate $X_{L}^{1}$, the set of types who at period $t=1$ announce to vote for $L$ :

$$
X_{L}^{1}=\left\{x \leq l_{1} \text {, where } l_{1}=1-F(1)\right\} .
$$

In a similar way the set of types who announce to vote for $R$ is

$$
X_{R}^{1}=\left\{x \geq r_{1} \text {, where } r_{1}=1-F(0)\right\} .
$$

Notice that (4) and (5) follow from the behavior described by (1). Agents at period $t=1$ believe that there is some positive probability that almost all undecided agents at $t=0$ vote for $L$. Were that the case, the implemented policy would be $l_{1}$ and then all agents with ideal points to the left of such number should vote for $L$ (a similar argument works for $r_{1}$ ). For the rest of periods we can define-in a similar way to $X_{L}^{1}$ and $X_{R}^{1}$-the set of types announcing their vote for $L$ and the set of types announcing their vote for $R$ :

$$
\begin{aligned}
& X_{L}^{t}=\left\{x \leq l_{t}, \text { where } l_{t}=1-F\left(r_{t-1}\right)\right\} \\
& X_{R}^{1}=\left\{x \geq r_{t}, \text { where } r_{t}=1-F\left(l_{t-1}\right)\right\} .
\end{aligned}
$$

Then the variables we need to analyze are $l_{t}$ and $r_{t}$ : at period $t$ agents with type in the interval $\left[l_{t}, r_{t}\right]$ are undecided and agents with type $x<l_{t}\left(x>r_{t}\right)$ will vote for $L$ $(R)$. Thus, given initial conditions $l_{0}=0, r_{0}=1$ the dynamic process to consider is given by the following system of equations:

$$
\begin{aligned}
& l_{t}=1-F\left(r_{t-1}\right) \\
& r_{t}=1-F\left(l_{t-1}\right) .
\end{aligned}
$$

If after, say, $s$ polls in each subsequent poll the interval of the undecided does not change, then the process has reached a steady state where $l_{s}=l_{s+t}=l^{*}$ and $r_{s}=r_{s+t}=r^{*}, t \geq 1$. Plugging the expression for $r_{t-1}$ into the expression for $l_{t}$ we get:

$$
l_{t}=1-F\left(1-F\left(l_{t-2}\right)\right) .
$$

This is a second order difference equation with initial values $l_{0}=0$ and $l_{1}=1-$ $F\left(r_{0}\right)=1-F(1)$.

Next, we will establish sufficient conditions for the sequence of polls to converge to the complete information outcome. First define

$$
h(x) \equiv 1-F(1-F(x)), x \in[0,1]
$$

Notice that the function $h(x)$ captures the dynamic in (8). 
Theorem 2 If $h^{\prime}(x)=F^{\prime}(1-F(x)) F^{\prime}(x)<1 \forall x \in[0,1]$ then a sequence of polls will converge to the complete information outcome.

Proof Notice that the complete information outcome, $x^{*}$, is a fixed point of $h(x)$. Indeed, since $x^{*}=1-F\left(x^{*}\right)$, we have that $h\left(x^{*}\right)=1-F\left(1-F\left(x^{*}\right)\right)=1-F\left(x^{*}\right)=x^{*}$. Therefore, if $h(x)$ has a unique fixed point it will be the complete information outcome and the (probably infinite) sequence of polls will make $l_{t}$ to converge to its complete information value. It is straightforward to see that in that case $r_{t}$ also converges to the complete information value. Uniqueness of $h(x)$ is not guaranteed however, and depends on the form of the distribution function $F(\cdot)$. Given that $h(x)$ is continuous and increasing, and $h(0)>0$, it is clear that the condition $h^{\prime}(x)<1$ in [0,1] is enough to guarantee that there is a unique fixed point in $[0,1]$.

The following straightforward corollary establishes when the sequence of polls will converge to a fixed point that could be different from the one associated to the complete information one.

Corollary 1 Let $\underline{x}^{*}$ be the smallest fixed point of $h(x)$. A sufficient condition for $l_{t}$ to converge to $\underline{x}^{*}$ is that $F^{\prime}(1-F(x)) F^{\prime}(x)<1$ holds for all $x \in\left[0, \underline{x}^{*}\right]$.

Therefore, if $F^{\prime}(1-F(x)) F^{\prime}(x)<1$ holds in $[0,1]$ then the complete information outcome is a unique fixed point of $h(\cdot)$, and a sequence of possibly infinite polls will converge to it. In absence of fixed point uniqueness Corollary 1 also tells us that if there is a fixed point $\underline{x}^{*}$ such that $\underline{x}^{*}<x^{*}$ with $x^{*}$ being the fixed point corresponding to the complete information outcome, and if $F^{\prime}(1-F(x)) F^{\prime}(x)<1$ is satisfied in the interval $\left[0, \underline{x}^{*}\right]$, then we will have a mass of undecided voters located in $\left[\underline{x}^{*}, \bar{x}^{*}\right]$, with $\bar{x}^{*}=1-F\left(\underline{x}^{*}\right)$. In this case, the polls cannot lead to complete information, and there will always be some positive mass of undecided voters in $\left[\underline{x}^{*}, \bar{x}^{*}\right]$, no matter how many polls will be conducted afterwards.

Inequality $F^{\prime}(1-F(x)) F^{\prime}(x)<1$ may seem a little strange; however it can be intuitively explained in the case of a symmetric distribution of the undecided at period 0 . It provides a sort of upper bound on the maximum of the probability density function or, putting it differently, an implicit lower limit on the variance of the distribution. When most of the mass of the undecided is located close to the mean of the distribution, their influence in the election is potentially so large that there can be no improvement in information in the sense of having less undecided agents.

To illustrate the insight of the Theorem, we provide a couple of examples with different voters' preferences distributions. First, assuming that $F$ is uniform on the interval $D=\left[-q_{L}, 1+q_{R}\right]$, we have that:

$$
F^{\prime}(1-F(x)) F^{\prime}(x)=\frac{1}{\left(1+q_{R}+q_{L}\right)^{2}} .
$$

Given $q_{R}+q_{L}>0$, then $\frac{1}{\left(1+q_{R}+q_{L}\right)^{2}}<1$, therefore the sufficient condition for uniqueness and convergence holds for all $x \in[0,1]$. On the other hand, a symmetric triangle distribution with small masses of partisan voters provides an extreme case for which the condition fails. In fact, a simple numerical application shows that for 

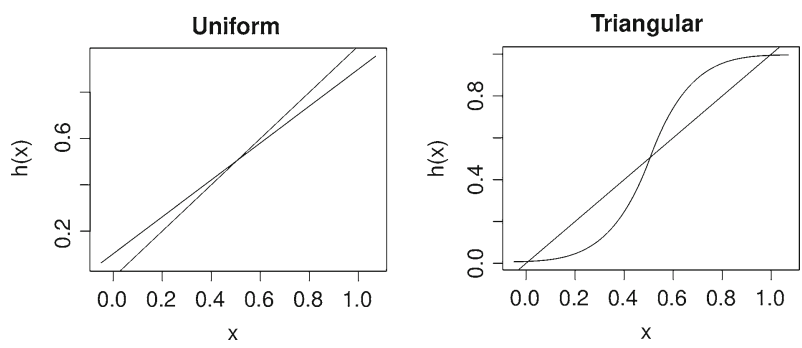

Fig. 1 Examples of $h(x)$

$q_{L}=0.05$ and $q_{R}=0.07$ and the triangle distribution, polls cannot improve information that much since at least $98.5 \%$ of the voters in $[0,1]$ will remain undecided.

Figure 1 shows the plots of the $h(\cdot)$ function for the two cases mentioned above. In the uniform case, there exists only the fixed point corresponding to the complete information outcome which can be achieved with enough polls. In contrast, in the triangular distribution case, we can see that there are three fixed points: the complete information one, $x^{*}$, in the middle, the left one, $x_{l}$, where $l_{t}$ converges to, and the third one $x_{r}$, where $r_{t}$ converges to. It is easy to see that the condition for $l_{t}$ to converge to the complete information outcome does not in fact hold. The two non-middle fixed points define the interval where the minimum possible mass of undecided agents is located on.

In terms of the implemented policy, we can calculate for each poll what the implemented policy would be if that poll were the last one to be conducted. In this way we get a sequence of possible implemented policies associated with a given sequence of polls. If the sequence of polls converges to the complete information outcome, the corresponding sequence of implemented policies converges to $x^{*}$. Otherwise, it converges to an implemented policy that lies somewhere in $\left[\underline{x}^{*}, \bar{x}^{*}\right]$. Regardless of where the sequence of possible implemented polices converges to, this convergence is not necessarily monotonic in the number of polls. Thus, in general there is no way to know if one extra poll before the election will bring the implemented policy closer to the complete information policy or not.

In the Appendix, we examine an extension of the model that allows for some day-today political noise that can shift the ideological position of the agents to the left or the right. The only significant difference is that in this case the polls can never help reach the complete information outcome, so there will always be some undecided voters. This extension provides some other interesting insights. In fact one implication is that the results of the model can follow even with potentially biased polls or with agents lying, as long as the bias is relatively small. What this means is that if the results of polls are biased and this bias is a random variable with a known support, the voters can still calculate minimum and maximum implemented policies by taking into account the most extreme cases of bias possible. If the bias is relatively small the mechanism of the model still works with the only difference that in this case polls can never bring the society to complete information. On the other hand, if the bias is relatively large, polls are unable to offer any information to the undecided voters. 
An important assumption that we have maintained so far is that agents respond honestly to polls. Even though this might be seen as a strong assumption, the alternative model with fully strategic agents would be intractable. Moreover, the discussion in the Appendix shows that our model can deal with the case in which some partisan voters might misrepresent their views as long as the share of such strategic agents is not too large.

\section{Conclusions}

In this paper we examine a proportional representation voting model with polls in which the distribution of voter preferences is unknown. The model provides three predictions, that to the best of our knowledge cannot all three be replicated by any other model. First, the lack of monotonicity of the shares of parties in the number of polls, second, the mass of undecided voters is decreasing in the number of polls, and third, there is a positive correlation between having a centrist ideology and being undecided. The most important finding of the paper is that although each poll weakly decreases the mass of undecided voters, a sequence of polls may not always be able to decrease this mass to zero and reveal the complete information outcome to the voters. On top of that, there might be polls that actually push the society away from the complete information case: if the last poll before the election is such a poll, and we are interested in having an election result as close to the complete information as possible, this poll should not have happened. On the other hand, this negative effect can be remedied by having a new additional poll. Without information about how the distribution of preferences looks like we cannot know if the final extra poll before the election has a beneficial effect or not. However, if the number of polls is sufficiently large the outcome approaches as much as possible to the complete information case.

Acknowledgements We would like to especially thank Antoine Loeper for his comments. We would also like to thank N. Tsakas, P. Denter, M. Serena, A. Casas, J. Stuhler, M. Celentani, D. Lougee, L. Corchón, B. Schmidpeter, O. Troumpounis, J. Esteban, E. Aragonès and H. Mueller for their comments and for useful discussions, as well as participants in seminars in Universidad Carlos III de Madrid, Universitat Autònoma de Barcelona, Universitá di Modena e Reggio Emilia and the Fourteenth Conference on Research on Economic Theory and Econometrics. Part of this paper was written while Mavridis was a PhD student at Universidad Carlos III de Madrid. Ortuño-Ortín acknowledges financial support form the Spanish Ministry of Economics and Competitiveness, Grant ECO2016-75992-P and MDM 2014-0431, and from Comunidad de Madrid, MadEco-CM (S2015/HUM-3444).

\section{Compliance with ethical standards}

Conflict of interest The authors declare they have no conflicts of interest.

Open Access This article is distributed under the terms of the Creative Commons Attribution 4.0 International License (http://creativecommons.org/licenses/by/4.0/), which permits unrestricted use, distribution, and reproduction in any medium, provided you give appropriate credit to the original author(s) and the source, provide a link to the Creative Commons license, and indicate if changes were made.

\section{Appendix: Position uncertainty}

Even though the voters have preferences over the implemented policy, it can often be the case that their opinions can change from day to day, due to random political 
noise. The assumption that this section maintains is that, while a voter's ideological position can change due to random shocks, this position will not move too far away from her initial ideological position. We will model this by assuming that the optimal policy for a voter with initial position $x$ can move randomly around a small interval $[x-e, x+e]$, with $e>0$. This is the only difference with the previous model. That is each voter's optimal policy can change from day to day, moving randomly in this small interval. For simplicity we assume that partisan voters do not get the shock.

The timing of the new set-up is as follows. At time $t$ the agents calculate $\left[l_{t}, r_{t}\right]$, a poll takes place to which the agents respond truthfully and then a shock takes place. Afterwards we can have the election, or we start over with a new poll. The shock is not necessarily common to all voters. Each voter $x$ is aware of her initial optimal policy and the interval $[x-e, x+e]$ that her future optimal policy can fall into. Notice that under this setting (with the exception of partisan voters), agents who are located in $\left[l_{t}-e, l_{t}\right]$ can no longer announce that they will vote for $L$ : they understand that in the future, because of the random shock, they might find themselves on the other side of $l_{t}$. Similarly, agents who are in $\left[r_{t}, r_{t}+e\right]$ cannot announce they will vote for $R$. From this example it should be clear that the interval where undecided voters fall in each period is simply $\left[l_{t}-e, r_{t}+e\right]$, and that the sets of types that announce that they will vote for $L$ and $R$ in period $t$ become:

$$
\begin{aligned}
& X_{L}^{t}=\left\{x \leq l_{t}^{\prime}, \text { where } l_{t}^{\prime}=l_{t}-e\right\} \\
& X_{R}^{t}=\left\{x \geq r_{t}^{\prime}, \text { where } r_{t}^{\prime}=r_{t}+e\right\} .
\end{aligned}
$$

The dynamic process is now:

$$
\begin{aligned}
& l_{t}=1-F\left(r_{t-1}^{\prime}\right) \\
& r_{t}=1-F\left(l_{t-1}^{\prime}\right) .
\end{aligned}
$$

Rewriting the previous two equations and plugging the second one into the other we get:

$$
l_{t}=1-F\left(1-F\left(l_{t-2}-e\right)+e\right) .
$$

If similarly to Sect. 2 we define the function:

$$
h_{e}(x)=1-F(1-F(x-e)+e),
$$

we see that all the conditions for the existence of a fixed point still hold. Now however, there is no fixed point that corresponds to full information in the sense we have defined it previously. In other words, there does not exist a fixed point where all the voters have made up their minds.

Proposition 1 Suppose that the uncertainty in voters' ideologies is as described in this Appendix. Then the complete information outcome cannot be achieved regardless the number of polls.

Proof Suppose not. Then there exists an $s$ such that $l_{s}^{\prime}=r_{s}^{\prime}=l_{s+1}^{\prime}=r_{s+1}^{\prime}=l_{*}^{\prime}=r_{*}^{\prime}$. Then by (10) we have:

$$
l_{*}-e=r_{*}+e
$$


or,

$$
l_{*}=r_{*}+2 e
$$

which is a contradiction as $l_{*}$ cannot be greater than $r_{*}$.

We can also see that results of Theorem 2 and Corollary 1 follow immediately using:

$$
F^{\prime}(1-F(x-e)+e) F^{\prime}(x-e)<1
$$

The natural next question is to find the fixed point that corresponds to the "second best", where the mass of the undecided voters is the lowest it can get. An obvious candidate fixed point is a point where $l_{*}=r_{*}=x^{*}$, that is, the point where there is no uncertainty about the position of the implemented policy anymore. Then, we will have $l_{*}^{\prime}=x^{*}-e$ and $r_{*}^{\prime}=x^{*}+e$.

Proposition 2 There is no fixed point of $h_{e}(\cdot)$ of the form $l_{*}=r_{*}=x^{*}$.

Proof Suppose that time $s$ is the first time we observe $l_{s}=r_{s}$. Then $l_{s+1}=1-F\left(r_{s}+e\right)$ and $r_{s+1}=1-F\left(l_{s}-e\right)$, showing that $l_{s+1} \neq r_{s+1}$.

Proposition 2 tells us that there cannot be a situation where there is no uncertainty about the implemented policy, which further implies that the ideological distance between the last voter to vote for $L$ and the first voter to vote for $R$ cannot be less than $2 e$. The exact distance cannot be pinned down without first knowing the voters' distribution function.

What we take from the preceding analysis is that the added uncertainty of preferences makes not only the full information outcome completely unattainable, but also puts a lower bound on the measure of undecided voters. As $e$ gets smaller we get as close as possible to full information.

If $e$ becomes too big $(e>1)$ then polls essentially break down: only the first poll improves the information of the individuals because the only agents to ever respond to the polls are the partisan ones.

\section{References}

Alesina A, Rosenthal H (1996) A theory of divided government. Econometrica 64(6):1311-1341

Baron DP (1994) Electoral competition with informed and uniformed voters. Am Polit Sci Rev 88(1):33-47

Bernhardt D, Duggan J, Squintani F (2009) Private polling in elections and voter welfare. J Econ Theory 144(5):2021-2056

Ceci SJ, Kain EL (1982) Jumping on the bandwagon with the underdog: the impact of attitude polls on polling behavior. Public Opin Q 46(2):228-242

Chung R (2012) The freedom to publish opinion poll results: a worldwide update of 2012. Tech. rep

De Sinopoli F, Iannantuoni G (2007) A spatial voting model where proportional rule leads to two-party equilibria. Int J Game Theory 35(2):267-286

Denter P, Sisak D (2015) Do polls create momentum in political competition? J Public Econ 130:1-14

Gerber A, Ortuño-Ortín I (1998) Political compromise and endogenous formation of coalitions. Soc Choice Welf 15(3):445-454

Goeree JK, Großer J (2006) Welfare reducing polls. Econ Theory 31(1):51-68

Großer J, Schram A (2010) Public opinion polls, voter turnout, and welfare: an experimental study. Am J Polit Sci 54(3):700-717 
Grossman GM, Helpman E (1996) Electoral special competition and special interest politics. Rev Econ Stud 63(2):265-286

Herrera H, Llorente-Saguer A, McMurray J (2015) The marginal voter's curse. Mimeo

Herrmann M (2014) Polls, coalitions and strategic voting under proportional representation. J Theor Polit 26(3):442-467

Kendall C, Nannicini T, Trebbi F (2015) How do voters respond to information? Evidence from a randomized campaign. Am Econ Rev 105(1):322-353

Klor EF, Winter E (2006) The welfare effects of public opinion polls. Int J Game Theory 35(3):379-394

Klor EF, Winter E (2014) On public opinion polls and voters' turnout. Mimeo

Llavador H (2006) Electoral platforms, implemented policies, and abstention. Soc Choice Welf 27(1):55-81

Matakos K, Troumpounis O, Xefteris D (2015) Turnout and polarization under alternative electoral systems. In: Schofield N, Caballero G (eds) The political economy of governance: institutions, political performance and elections. Springer International Publishing, Cham, pp 335-362

Matakos K, Troumpounis O, Xefteris D (2016) Electoral rule disproportionality and platform polarization. Am J Polit Sci 60(4):1026-1043

McKelvey RD, Ordeshook PC (1985) Elections with limited information: a fulfilled expectations model using contemporaneous poll and endorsement data as information sources. J Econ Theory 36(1):55-85

McMurray J (2017) Voting as communicating: mandates, multiple candidates, and the signaling voter's curse. Games Econ Behav 102:199-223

Meirowitz A (2005) Polling games and information revelation in the Downsian framework. Games Econ Behav 51:464-489

Morgan J, Stocken PC (2008) Information aggregation in polls. Am Econ Rev 98(3):864-896

Morton RB, Muller D, Page L, Torgler B (2015) Exit polls, turnout, and bandwagon voting: evidence from a natural experiment. Eur Econ Rev 77:65-81

Myatt DP (2017) A theory of protest voting. Econ J 127:1527-1567

Myerson RB, Weber RJ (1993) A theory of voting equilibria. Am Polit Sci Rev 87(1):102-114

Ortuño-Ortín I (1997) A spatial model of political competition and proportional representation. Soc Choice Welf 14:427-438

Ortuño-Ortín I (1999) A model of voting with incomplete information and opinion polls. IVIE WP-AD 99-25

Sahuguet N, Persico N (2006) Campaign spending regulation in a model of redistributive politics. Econ Theory 28:95-124

Saporiti A (2014) Power sharing and electoral equilibrium. Econ Theory 55(3):705-729

Taylor CR, Yildirim H (2010) Public information and electoral bias. Games Econ Behav 68(1):353-375 